\title{
Properties of low-density cement-bonded composite panels manufactured from polystyrene and jute stick particles
}

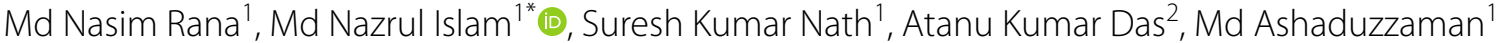 \\ and Md Iftekhar Shams ${ }^{1}$
}

\begin{abstract}
This study was conducted to evaluate the properties of cement-bonded composite (CBC) manufactured using jute stick particles and expanded polystyrene (EPS) beads to reduce the density of $C B C$ for mitigating the main limitation of CBC in its applications. The CBCs were manufactured by using cement, jute stick particle, EPS and jute fiber by cold pressing having the pressure of $5 \mathrm{MPa}$ and pressing time of $24 \mathrm{~h}$. CBCs were also manufactured by replacing the jute stick particles with EPS beads, the processing conditions remaining the same. There were at least 5 replications for each type of board. Waste jute fibers were added for improving the degenerated mechanical properties of CBC caused by the addition of EPS beads. Important physical properties, i.e., density, water absorption (WA) and thickness swelling (TS) and mechanical properties, i.e., modulus of elasticity (MOE) and modulus of rupture (MOR) of the manufactured CBCs were tested following the Malaysian Standards. Higher percentage of EPS beads significantly reduced the density of $\mathrm{CBCs}$ and the lowest density $\left(0.91 \pm 0.02 \mathrm{~g} / \mathrm{cm}^{3}\right)$ was found when the EPS beads replaced $30 \%$ jute stick particles. As expected, mechanical properties decreased with the gradual replacement of jute stick particles by EPS beads. However, the degraded mechanical properties significantly increased when waste jute fibers were added in the CBCs. Addition of EPS beads in CBCs reduced the density, which might increase the potentiality for the utilization of cement-bonded composites for various applications.
\end{abstract}

Keywords: Agricultural residues, Cement-bonded particleboard, Mineral binder, Physical properties, Mechanical properties

\section{Introduction}

Cement-bonded composites (CBCs) are emerging as an important class of construction materials made of cementitious matrix and fibers or particles [1] obtained from wood, agricultural residues and other natural origins [2-4]. However, the increased consumption of wood is causing depletion of the forest and need to be saved for the future $[3,5]$ in most of the countries. Whilst developing countries have accelerated the generation of wastes from agro-forestry-based industries like jute sticks, bagasse, rice husk and straw, wheat

\footnotetext{
*Correspondence: nazrul17@yahoo.com

${ }^{1}$ Forestry and Wood Technology Discipline, Khulna University,

Khulna 9208, Bangladesh

Full list of author information is available at the end of the article
}

straw, oil palm strands and from the demolition of old structures such as buildings, railways, telephone and fencing poles, bridges [1]. The utilization of these lignocellulosic wastes for making cement-bonded construction materials, a substantial materials consuming industry, offers an attractive alternative to their disposal and raw material for the industry of CBCs. This can also add a number of suitable features to the $\mathrm{CBCs}$ including low-density products, low requirements of processing equipment, negligible abrasion to the processing machinery and abundant raw material availability along with the forest conservation. In comparison to the resin-bonded composites, the advantages of CBCs are low processing temperature, low-cost binder, less air pollution and reduction in $\mathrm{CO}_{2}$ emission, better acoustic and thermal insulation, dimensionally stable 
and a finished product with better resistance to water, fire and biodegradation $[1,2,6]$. Alongside the construction, these materials have also the potentiality to use for furniture, packaging and decorative purposes [7-9].

Numerous studies were carried out on the production of $\mathrm{CBCs}$ using lignocellulosic materials by many researchers [1, 4, 9-14]. However, the development of CBCs has been slowed down by the lack of basic understanding of the mechanisms involved in the bonding of cement and lignocellulosic particles [15]. Additionally, these have higher density until now compared to the synthetic resin based panels [16], longer curing time [13] and water absorption [4]. Lignocellulosic materials contain many inhibitory substances, e.g., hemicelluloses, starches, sugars, phenols, hydroxylated carboxylic acids which dissolve during hydration of cement and affect its crystallization. This negative impact can be minimized by drying of lignocellulosic particles [17, 18] or washing the particles or using additives such as calcium chloride and sodium silicate $[19,20]$. Alternatively, injection of carbon dioxide in the mixture can significantly improve the wood-cement compatibility [13], which also reduces the water absorption properties of the panels [21], and promote rapid strength development for the composites [22]. However, larger amount of cement is used in the CBCs for bonding in comparison to particles (cement:particles ratio is higher than 3:1), thus, the final products have higher density $\left(>1.3 \mathrm{~g} / \mathrm{cm}^{3}\right)[2,4,23]$. This higher weight of the panel has a significant drawback and impedes this material against many applications as a commercial building component. Additionally, since cement is more expensive than wood residue, adding greater quantities of cement will increase panel raw material costs. The use of low-density non-wood lignocellulosic materials like jute stick, kenaf core, straws, rice husk might help to reduce the density of CBCs $[1,24,25]$ which can be further decreased by the addition of ultra-light weight materials, i.e., expanded polystyrene (EPS) beads [26, 27]. The addition of EPS beads to produce lightweight concrete is the fastest growing sectors in the building construction industry. However, not a single study has so far reported to use the EPS beads for the production of CBCs. Bangladesh, an agrarian country, produces a substantial quantity of agricultural residues every year, especially jute sticks which is obtained after separating the fiber becoming a waste and possess no/limited value [28]. Thus, this study was designed to produce lower density CBC by using the jute sticks particles and EPS beads for wider applications of CBCs. Retaining the strength after lowering the density by adding the waste jute fibers was also the objective of this study.

\section{Materials and methods}

Reinforcement particles, i.e., jute stick, waste jute fiber, EPS beads, and ordinary Portland cement (OPC), were collected from the local commercial market of Khulna district, Bangladesh. The properties of the collected EPS beads, jute stick particles and jute fiber in the study are summarized in Table 1. The collected EPS beads were stored in airtight packs until further use. The jute sticks were dried under the sun for 3 weeks. The sticks were then cut into small pieces, and the small pieces were converted into smaller particles using a grinder. The particle size ranged between 1 and $2 \mathrm{~mm}$ were collected by using the sieve. The bulk density of the jute stick particles was measured following SCAN-CM 46:92 standard [29]. Later, the jute fibers and particles were dried using an oven for 8 and $24 \mathrm{~h}$, respectively, at $103 \pm 2{ }^{\circ} \mathrm{C}$ to achieve the moisture content of less than $5 \%$. Distilled water was used as setting agent for OPC.

\section{Manufacturing of composite panels}

A constant ratio of cement, reinforcement particles and water (2.2:1.0:1.1, w/w basis) was used for manufacturing of all the panels using a constant pressure of $5 \mathrm{MPa}$ and time of $24 \mathrm{~h}$ at room temperature of $24 \pm 2{ }^{\circ} \mathrm{C}$ [30]. Jute stick particles, EPS beads and jute fibers were mixed in the panels at varying ratio (w/w basis) of 100,0 , and 0 ; 95, 5 and 0 ; 90, 10 and $0 ; 88,12$ and $0 ; 85,15$ and $0 ; 82$, 18 and $0 ; 80,20$ and $0 ; 75,25$ and $0 ; 70,30$ and $0 ; 70,27.5$ and 2.5; 70, 25 and 5; 70, 22.5 and 7.5; and 70, 20 and 10 as shown in Table 2 .

All the raw materials, i.e., OPC, jute stick particles, EPS beads, waste jute fibers and water, were mixed for each type of board in a rotary drum blender and blended for $6 \mathrm{~min}$ to get a homogenous mixture of the components. For CBCs containing waste jute fibers, OPC was pre-blended with waste jute fibers in a highspeed blender and then placed into the rotary drum blender with other components. A standardized mat was formed using the mixture expecting a panel thickness of $8 \mathrm{~mm}$ in a forming box on aluminum caul plate.

\begin{tabular}{llll}
$\begin{array}{l}\text { Table } \mathbf{1} \\
\text { Physical } \\
\text { of the collected jute stick, waste jute fiber and EPS beads }\end{array}$ & $\begin{array}{c}\text { and } \\
\text { properties }\end{array}$ \\
\hline Property & \multicolumn{2}{c}{ Average value } \\
\cline { 2 - 4 } & Jute stick & Waste jute fiber & EPS beads \\
\hline $\begin{array}{l}\text { Density }\left(\mathrm{g} / \mathrm{cm}^{3}\right) \\
\text { Flexural strength }(\mathrm{MPa})\end{array}$ & -0.18 & 0.41 & 0.01301 \\
$\begin{array}{l}\text { Compressive strength } \\
\text { (MPa) }\end{array}$ & - & - & 0.221 \\
Water absorption & - & - & 0.09 \\
\hline
\end{tabular}


Table 2 Ratios of reinforcing materials for the fabrication of different types of CBC

\begin{tabular}{lllll}
\hline Board types & $\begin{array}{l}\text { Shorthand } \\
\text { notation }\end{array}$ & \multicolumn{2}{l}{$\begin{array}{l}\text { Percentages of jute particles, EPS } \\
\text { and jute fiber (w/w basis) }\end{array}$} \\
\cline { 3 - 5 } & & $\begin{array}{l}\text { Jute } \\
\text { particles } \\
(\%)\end{array}$ & EPS (\%) & Jute fiber (\%) \\
& & 100 & 0 & 0 \\
\hline 1 & Control & 95 & 5 & 0 \\
2 & PB-5 & 90 & 10 & 0 \\
3 & PB-10 & 12 & 0 \\
4 & PB-12 & 88 & 15 & 0 \\
5 & PB-15 & 85 & 15 & 0 \\
6 & PB-18 & 82 & 18 & 0 \\
7 & PB-20 & 80 & 20 & 0 \\
8 & PB-25 & 75 & 25 & 0 \\
9 & PB-30 & 70 & 30 & 2.5 \\
10 & PBJF-2.5 & 70 & 27.5 & 5 \\
11 & PBJF-5 & 70 & 25 & 7.5 \\
12 & PBJF-7.5 & 70 & 22.5 & 10 \\
13 & PBJF-10 & 70 & 20 & \\
\hline
\end{tabular}

The mat was then pressed in a single daylight cold press following the manufacturing parameters mentioned above. The manufactured panels were conditioned at room temperature for 28 days when water was sprayed twice in a day for proper curing of the boards [31]. Five panels were produced for each type of the sample. All the manufactured panels were trimmed to a size of $35 \times 25 \times 0.7 \mathrm{~cm}$ and dried at room temperature for 28 days before testing of the properties.

\section{Evaluation of physical and mechanical properties of the samples}

The physical properties, i.e., density, water absorption (WA) and thickness swelling (TS) and mechanical properties, i.e., modulus of rupture (MOR) and modulus of elasticity (MOE) of the manufactured CBCs were tested according to the Malaysian Standards for Wood Cement Boards [32]. The testing samples were prepared following the standard and put into a conditioning room $\left(24 \pm 2{ }^{\circ} \mathrm{C}\right.$ temperature and $60 \pm 2 \%$ relative humidity) for $24 \mathrm{~h}$ before testing of the properties. Density of the samples was determined by measuring the dimension and weight of the samples. WA and TS of the samples were determined after 2 and $24 \mathrm{~h}$ of immersion of samples in water. MOE and MOR of the samples were determined by the three-point bending test using universal testing machine (SHIMADZU AG-50KNXplus, Japan). There were 10 samples for testing each of the physical and mechanical properties.

\section{Statistical analysis}

Data analysis was performed using 'RStudio' version 1.1.463 [33]. The descriptive statistics (means, standard deviation (SD), standard error (SE), etc.) were calculated using the 'psych' package [34]. Normality and homogeneity were tested with the 'car' package [35]. An analysis of variance (ANOVA) model and least significant difference (LSD) test were also applied with the 'car' package at 5\% significance level. All graphs were made with the 'ggplot2' package [36].

\section{Results and discussion Physical properties}

The lowest density $\left(0.91 \mathrm{~g} / \mathrm{cm}^{3}\right)$ among the manufactured CBCs was observed for the PB-30 board while the highest density $\left(1.32 \mathrm{~g} / \mathrm{cm}^{3}\right)$ was observed for the control one. The density of the manufactured CBCs decreased gradually with the increase of EPS beads percentage (Fig. 1). However, gradual addition of jute fiber with the EPS beads did not increase the density significantly though this addition regenerated the relapsed strength properties. The density of the board is dependent on compaction of the mat, pressing pressure, particle size and the density of raw material and binding agent [37]. In this study, density of raw materials $\left(0.180 \mathrm{~g} / \mathrm{cm}^{3}\right.$ for jute stick particles and $0.01301 \mathrm{~g} / \mathrm{cm}^{3}$ for EPS beads) was lower compared to the binding agent, i.e., Portland cement $\left(1.44 \mathrm{~g} / \mathrm{cm}^{3}\right)$. Thus, the lower density of lignocellulosic raw materials helped to bring down the final density of the board. The variability of density was dependent on the raw material combination and their compaction due to having particle-particle bondability since the pressure and cement ratio were constant for all of the boards. Hydroxyl $(\mathrm{OH})$ group is responsible for making bond with particles in the cement-bonded particleboard, which increases the compactness among particles resulting in higher density of the manufactured particleboard [27]. Special surface criteria of lignocellulosic material, i.e., fiber origins interfacial interactions such as adhesion to non-polar and polar materials help to make a strong bond with lignocellulosic and inorganic particles; this enhances the compactness in the board matrix [38, 39]. On the other hand, EPS beads, which are inert material, cause small voids by the reduction of inter-particle bondability [27]. Therefore, the increasing percentage of inert EPS beads by replacing the jute stick particles in the panel reduced the number of $\mathrm{OH}$ groups and thus, reduced the bonding strength among particles, which ultimately lowered the density of board with higher percentage of EPS beads (Fig. 1). This is again improved by the addition of lignocellulosic fiber (waste jute fibers) replacing the EPS beads resulted higher density illustrated in Fig. 1. The minimum density requirement for $\mathrm{CBC}$ is 1.00 and $1.25 \mathrm{~g} /$ 


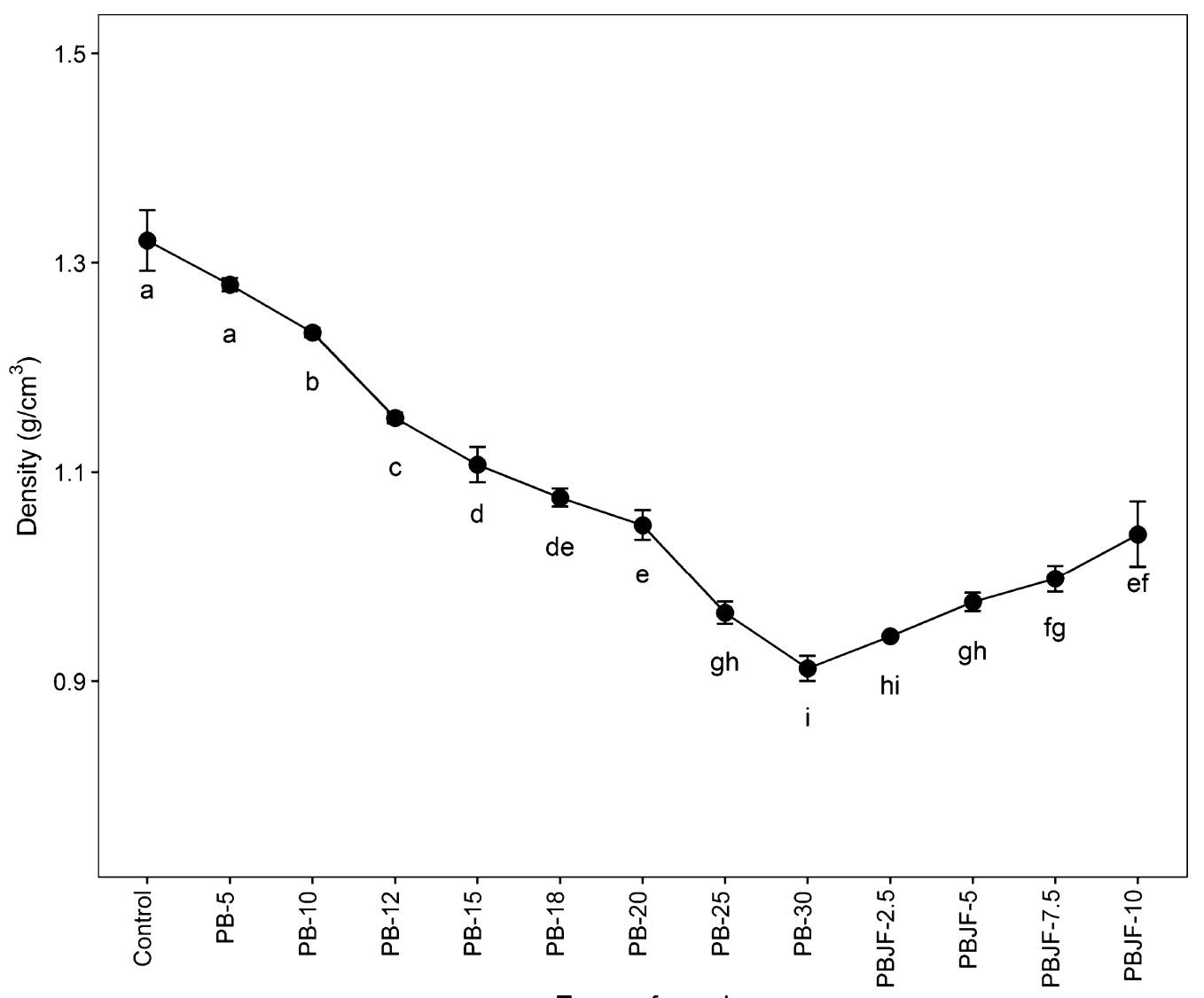

Types of panel

Fig. 1 Density variation for different types of CBCs produced using different raw materials. Different letters below each point indicate statistically significant differences among groups $(p<0.05)$

$\mathrm{cm}^{3}$ according to ISO 8335 [40] and IS 14276 [41] standards, respectively. Density of the manufactured control and $\mathrm{PB}-5$ panel met the minimum requirement of all the standards [40, 41]. Different lignocellulosic particles were used to produce CBCs by different researchers $[4,23,27]$ where the density ranged between 1.0 and $1.80 \mathrm{~g} / \mathrm{cm}^{3}$ because of the raw materials variations, and it was higher than the present study. Statistical analysis indicated that there was significant difference $(p<0.05)$ among the densities obtained from the different manufactured CBCs.

WA was observed after 2 (WA2) and $24 \mathrm{~h}$ (WA24) of immersion of samples in water. WA after $2 \mathrm{~h}$ (WA2) was lower than that of $24 \mathrm{~h}$ (WA24) for each type of panel (Fig. 2). The soaking time has the effect on the WA, i.e., WA increases with the increase of soaking time [42]. As expected, the addition of hydrophobic EPS beads in CBC decreased WA of the manufactured panels for both after 2 and $24 \mathrm{~h}$ of immersion and it decreased more by the addition of higher percentage of EPS beads in the mixture (Fig. 2). Water absorption is affected by the polarity and size of material; the lignocellulosic polar material, which contains $\mathrm{OH}$ group in cellulose, has a tendency to absorb more moisture [4, 37, 43]. EPS beads are nonpolar and they do not have affinity to water [27], thus, retarding water absorption water by the panel even after adding small quantity of fiber in this study. The EPS beads reduced the capillary porosity of the board, and it is one of the reasons for this lower water absorption for the CBC [11]. Additionally, EPS beads reduced the amount of hydrophilic $\mathrm{OH}$ group in the CBCs resulting in lower water absorption. Thus, water absorption was higher when there was higher amount of jute stick particles in the CBCs. It was observed that PBJF-10 showed the lowest water absorption of 9.12 and $16.73 \%$ after 2 and $24 \mathrm{~h}$ of immersion, respectively, for both of the cases, while the control had the highest water absorption of 16.96 and $24.38 \%$ after 2 and $24 \mathrm{~h}$ of immersion, respectively. The addition of jute fiber may cause strong $\mathrm{OH}$ bond with jute stick particle and suppressed the TS, which may reduce the water absorption for jute fiber induced panels in this study. According to the IS 14276 standard [41], the maximum WA for CBCs is 13 and 25\% 


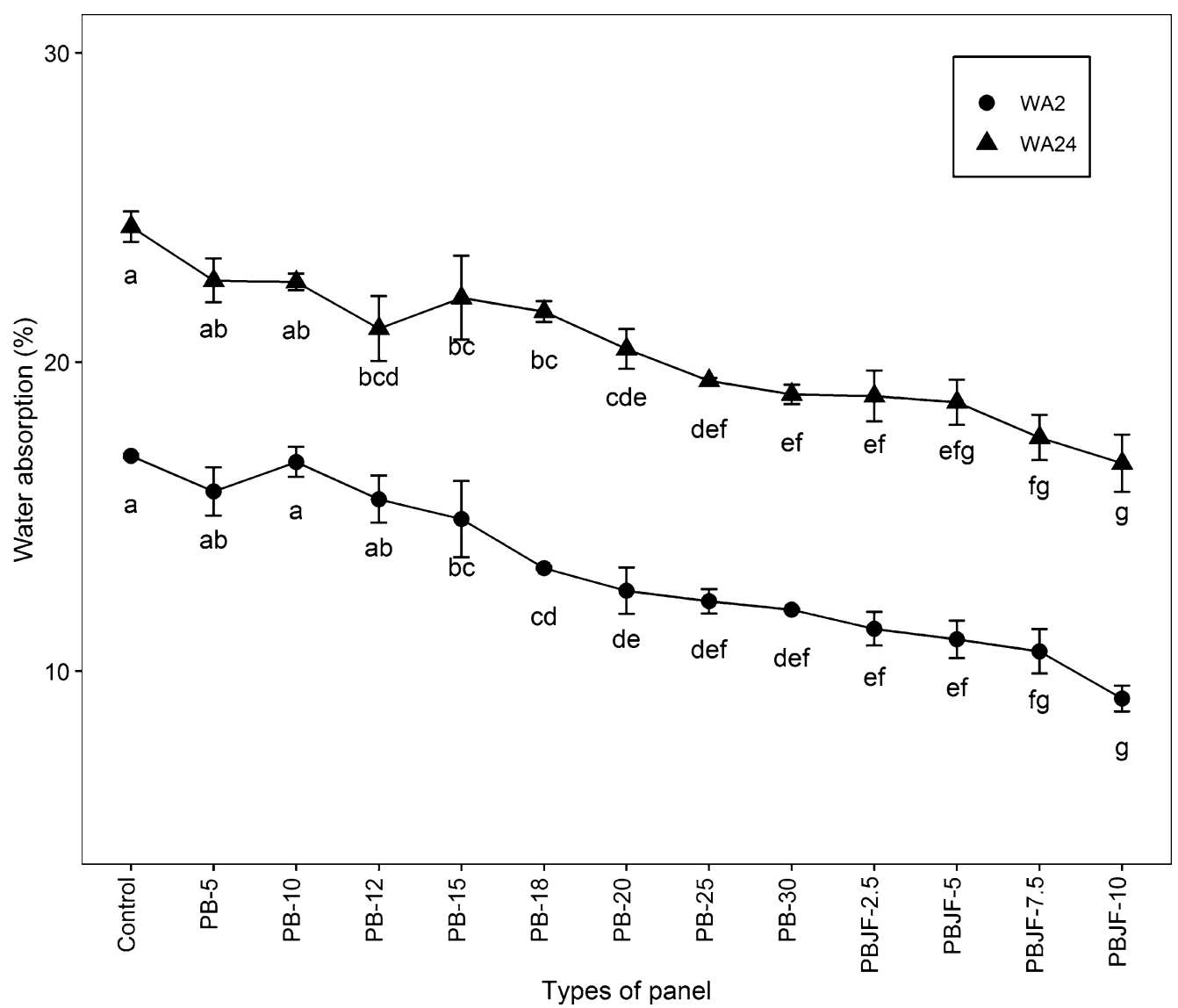

Fig. 2 Water absorption variation for different types of CBCs after 2 and $24 \mathrm{~h}$ of immersion in water. Different letters below each point indicate statistically significant differences among groups $(p<0.05)$

for 2 and $24 \mathrm{~h}$, respectively. Addition of waste jute fibers with EPS helped to follow the IS 14276 standards [41] for water absorption. Because of the use of cement as binder, WA is always higher in the CBCs, and it was at least $20 \%$ after $2 \mathrm{~h}$ of immersion and $32.5 \%$ after $24 \mathrm{~h}$ of immersion according to the different studies [23, 44]. Compared to the previous studies, water absorption both after 2 and $24 \mathrm{~h}$ of immersion was lower in the study, however, it varied significantly $(p<0.05)$ among the manufactured different types of CBCs.

As can be seen from Fig. 3, TS followed the trend of water absorption where $24 \mathrm{~h}$ of immersion had higher percentage of TS compared to the $2 \mathrm{~h}$ of TS for all the cases. TS of the manufactured CBCs increased with the increase of EPS beads; however, it decreased when waste jute fibers were added in the mixer. EPS beads decreased the WA, however, increased the thickness swelling as the trapped air in EPS beads start to expand during water absorption creating more open space, which allows more swelling resulting in weaker bonding strength [27]. Alongside water absorption, the deformed jute stick particles also initiate swelling for restoring original forms, which decreases the bonding strength between jute stick particles and cement resulting in the expansion of the deformed EPS beads. Addition of waste jute fibers in $\mathrm{CBCs}$ forms a network with polar, i.e., jute stick particle and jute fiber and non-polar, i.e., EPS beads materials through higher $\mathrm{OH}$ groups in cellulose of jute fibers compared to jute stick particles in the CBCs matrix [4]; thus, this strong network arrests the TS of the panel made with jute fibers. The highest TS was 3.15 and $4.18 \%$, respectively, for 2 and $24 \mathrm{~h}$ of immersion in water, when the CBCs contained the highest amount of EPS beads (30\%). According to ISO 8335 standard [40], the acceptable range of TS was $2.0 \%$ after $2 \mathrm{~h}$ of immersion in water. There was higher TS in comparison to the standard for CBCs in the present study.

\section{Mechanical properties}

The values of modulus of elasticity (MOE) for the manufactured CBCs are shown as a variation of MOE of different types of boards in Fig. 4. MOE decreased with 


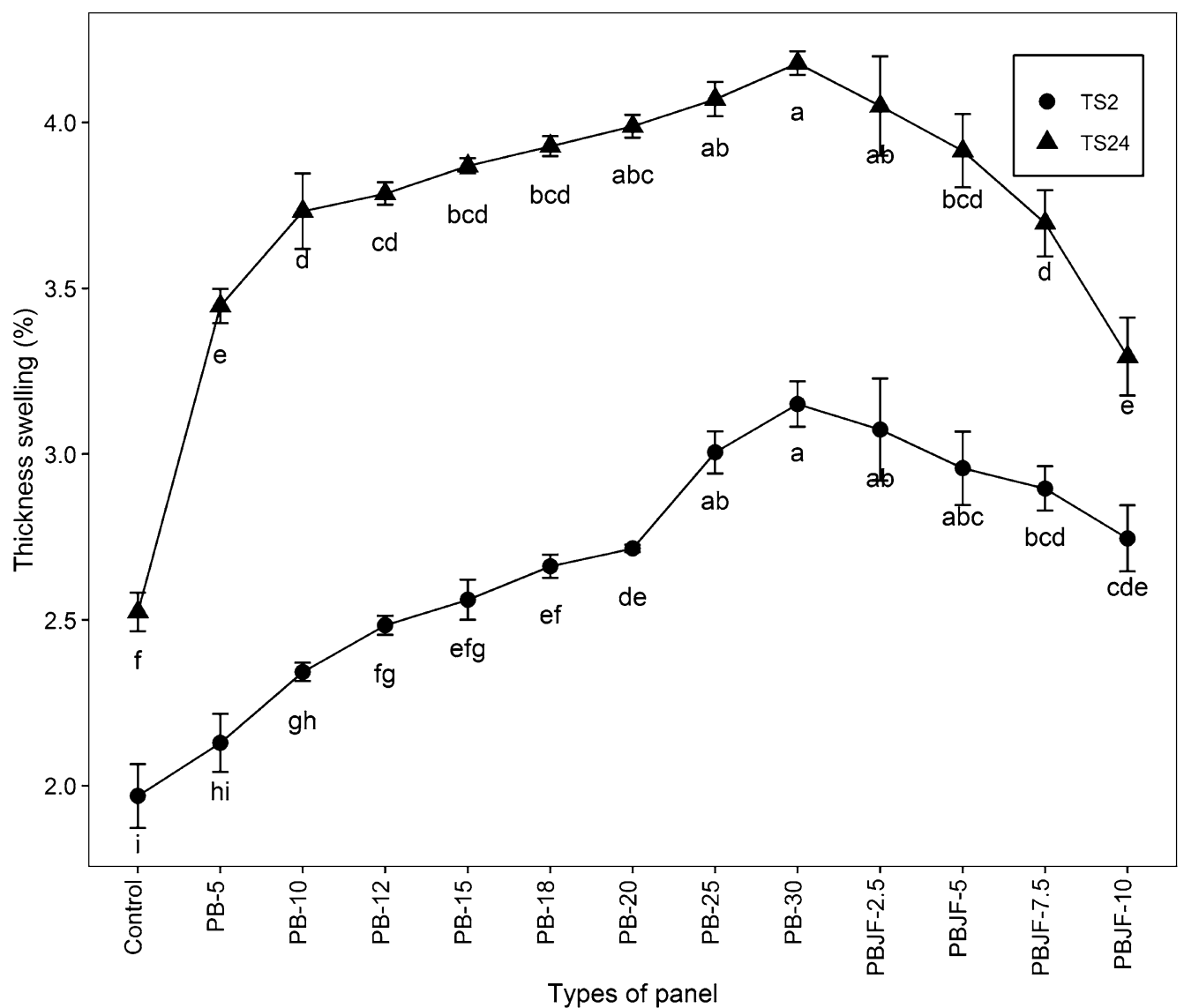

Fig. 3 Thickness swelling variation for different types of CBCs after 2 and $24 \mathrm{~h}$ of immersion in water. Different letters below each point indicate statistically significant differences among groups $(p<0.05)$

the increase of EPS beads percentage, however, addition of jute fiber with the EPS beads once again increased the MOE, which was even more than the controlled one during incorporation of $10 \%$ jute fiber. The highest MOE (4072 MPa) was found for PBJF-10, and the lowest $(1252 \mathrm{MPa})$ was found for the $\mathrm{PB}-30 \mathrm{CBC}$. As per the investigation of Maloney [45], the MOE of particleboards depends on particle quality, compaction and density of board. EPS beads have higher void volume, thus, these have lower strength. During the pressing of EPS beads, most of the air goes out, however, some voids still remain reducing the bondability among the $\mathrm{OH}$ groups [27]. Incorporation of jute fiber with homogenous distribution in the $\mathrm{CBCs}$ results in better fiber matrix bond through $\mathrm{OH}$ group in cellulose [4] and thus, it increased the MOE. Savastano Jr et al. [46] also reported similar results and mentioned that addition of fiber increased flexural strength, toughness, reinforcing efficiency and durability. Fiber is longer compared to particles and it transfers the stress from one fiber to another [47] resulting in higher MOE for the panel. Earlier studies had found very low MOE ranging from 28.81 to $428.95 \mathrm{MPa}$ when the researchers produced EPS beads-based concrete without pressure [23, 27]. The MOE was increased with the increase of board density (Fig. 5) and similar trends were also observed between density and MOE by previous researchers $[48,49]$. According to ISO 8335-87 standard, the MOE requirement of cement-bonded panel is $3000-4500 \mathrm{MPa}$. Some of the manufactured CBCs met the requirement of standard MOE.

As can be seen in Fig. 5, MOR was the highest (9.15 MPa) for the controlled $\mathrm{CBC}$, while PB-25 showed the lowest MOR (3.24 MPa). The MOR decreased sharply at the beginning and continued until the addition of $12 \%$ EPS beads; however, further EPS beads addition did not change the MOR significantly. Addition of waste jute fibers increased the MOR gradually. Factors affecting the MOR are particle quality, panel compaction and density of board [45]. Addition of EPS beads in CBCs reduced the bonding strength as described by Shalbafan et al. [27], and this strength reduction was optimum when there were $12 \%$ EPS beads in the mixture. Introduction 


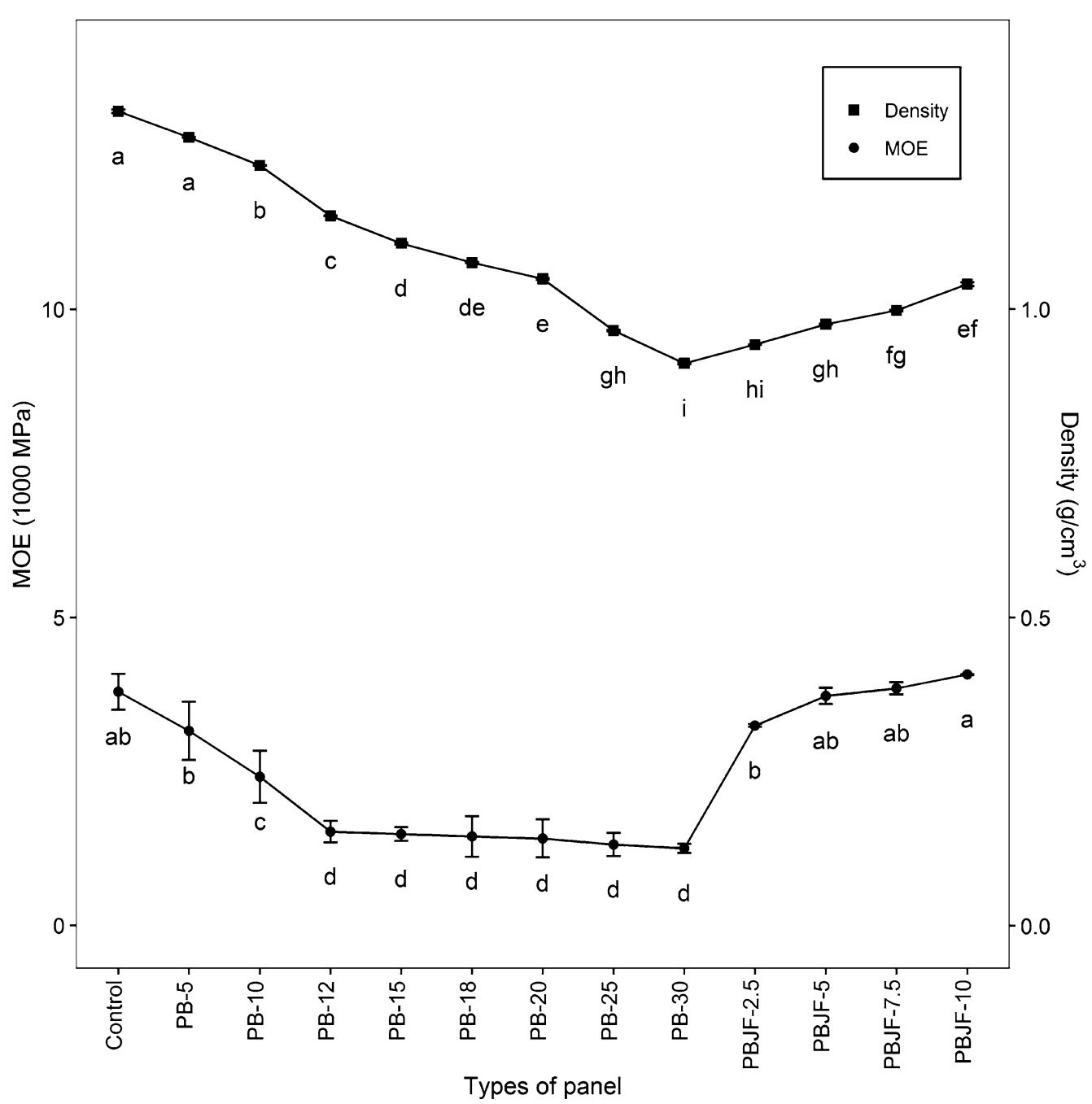

Fig. 4 Modulus of elasticity and density variation for different types of CBCs. Different letters below each point indicate statistically significant differences among groups $(p<0.05)$

of waste jute fibers in the CBCs with EPS beads increased the bondability as well as compaction because of the presence of $\mathrm{OH}$ group in it resulting in higher flexural strength, toughness, reinforcing efficiency and durability, which were reported by Savastano Jr et al. [46] and Mendes et al. [4]. The density of the board was highly associated with MOR in this study. Researchers also observed similar trend in their previous studies [50]. Ghosh et al. [23] reported lower MOR (0.98-2.46 MPa and 5.38-15.45 MPa) when lignocellulosic particles were used to make CBCs. Similar results were also reported in previous study [12] where the authors found very low MOR. According to ISO 8335-87 standard, the MOR requirement of cement-bonded panel is $9-10 \mathrm{MPa}$. Some of the manufactured cement-bonded composites met the MOR requirements.

\section{Conclusions}

Low-density cement-bonded particleboards $\left(<1.0 \mathrm{~g} / \mathrm{cm}^{3}\right)$ can be manufactured using jute stick particles and EPS beads following the procedure presented in this study. The thickness swelling of the boards was higher $(3.15$ and $4.18 \%$, respectively, for 2 and $24 \mathrm{~h}$ of immersion in water when $30 \%$ EPS beads were incorporated in CBCs) than that of standard. On the other hand, the mechanical properties of the boards were lower (1252 and 3.24 MPa for MOE and MOR, respectively). Nevertheless, the inclusion of jute fiber with the EPS beads significantly improved the mechanical properties (4072 and 9.12 MPa for MOE and MOR, respectively) and thickness swelling ( 2.75 and $3.2 \%$, respectively, after 2 and $24 \mathrm{~h}$ of immersion) though density increased a bit. Hence, this lower density and higher strength lignocellulose-based CBCs 


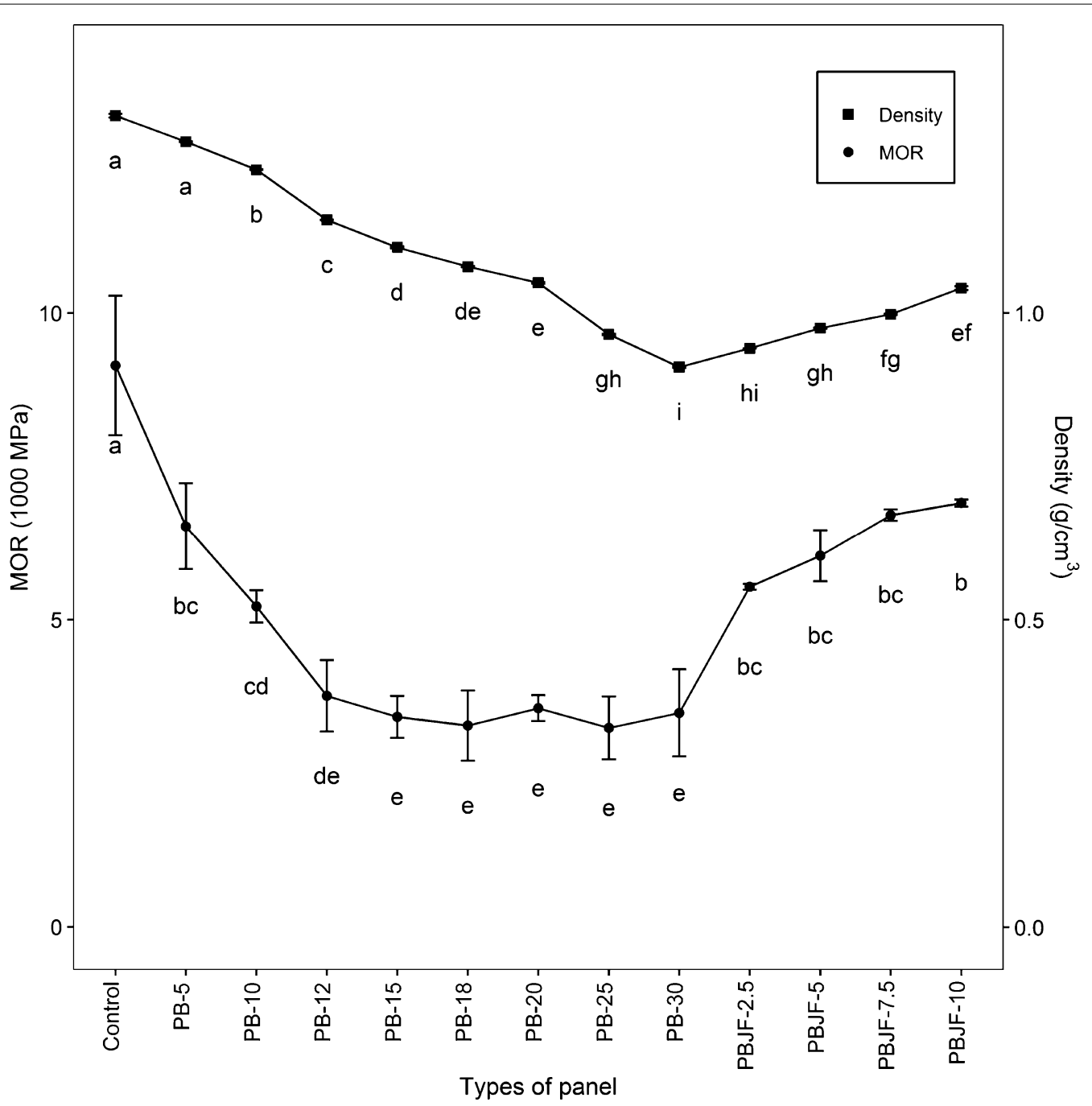

Fig. 5 Modulus of rupture and density variation for different types of CBCs. Different letters below each point indicate statistically significant differences among groups $(p<0.05)$

can be a very versatile material to be used for a variety of applications and get rid of formaldehyde-based lignocellulosic composites. However, further study is needed to optimize the production conditions and mixing ratios of jute fiber and EPS beads to obtain lower density panel with higher mechanical properties and less TS.

\section{Abbreviations}

CBC: cement-bonded composite; CBCs: cement-bonded composites; EPS: expanded polystyrene; SD: standard deviation; SE: standard error; ANOVA: analysis of variance; LSD: least significant difference; WA: water absorption; TS: thickness swelling; MOE: modulus of elasticity; MOR: modulus of rupture.

\section{Acknowledgements}

This research was supported by World Bank through Ministry of Education, Bangladesh, and University Grants Commission of Bangladesh. The title of the project is Higher Education Quality Enhancement Project (HEQEP) and the sub-project number is CP 4035 under Window 4, Phase 2. The authors are thankful to Professor Dr. Md Nabiul Islam Khan, Forestry and Wood Technology Discipline, Khulna University, Bangladesh, for his contribution to data analysis and graphical presentation.

\section{Authors' contributions}

MNI performed the research plan and MNR collected the data for evaluating the properties of cement-bonded board. SKN, AKD and MA performed the literature search. MNR, MNI and MIS performed the data analysis. MNR, SKN and AKD prepared the first draft of the manuscript. MNR and MNI were the major contributors for finalizing the manuscript. All authors read and approved the final manuscript.

\section{Funding}

Higher Education Quality Enhancement Project (HEQEP), CP 4035 by the World Bank under Ministry of Education, Bangladesh, through Bangladesh University Grants Commission (UGC).

\section{Availability of data and materials}

The datasets used and/or analyzed during the current study are available from the corresponding author on reasonable request. 


\section{Competing interests}

The authors declare that they have no competing interests.

\section{Author details}

${ }^{1}$ Forestry and Wood Technology Discipline, Khulna University, Khulna 9208, Bangladesh. ${ }^{2}$ Department of Forest Biomaterials and Technology, Swedish University of Agricultural Sciences, 90183 Umeå, Sweden.

Received: 7 August 2019 Accepted: 6 October 2019 Published online: 17 October 2019

\section{References}

1. Karade SR (2010) Cement-bonded composites from lignocellulosic wastes. Constr Build Mater 24(8):1323-1330

2. Frybort S, Mauritz R, Teischinger A, Müller U (2008) Cement bonded composites - a mechanical review. BioResources 3:602-626

3. Hm Akil, Omar MF, Mazuki AAM, Safiee S, Ishak ZAM, Abu Bakar A (2011) Kenaf fiber reinforced composites: a review. Mater Des 32:4107-4121

4. Mendes RF, Vilela AP, Farrapo CL, Mendes JF, Tonoli GHD, Mendes LM (2017) Lignocellulosic residues in cement-bonded panels. In: Savastano H Jr, Fiorelli J, dos Santos SF (eds) Sustainable and nonconventional construction materials using inorganic bonded fiber composites. Elsevier, Amsterdam, pp 3-16

5. Sotannde OA, Oluwadare AO, Ogedoh O, Adeogun PF (2012) Evaluation of cement-bonded particle board produced from Afzelia africana wood residues. J Eng Sci Technol 7:732-743

6. Soares Del Menezzi CH, Gomes de Castro V, Rabelo de Souza M (2007) Production and properties of a medium density wood-cement boards produced with oriented strands and silica fume. Maderas Ciency Tecnol 9:105-115

7. Binici H, Eken M, Dolaz M, Aksogan O, Kara M (2014) An environmentally friendly thermal insulation material from sunflower stalk, textile waste and stubble fibers. Constr Build Mater 51:24-33

8. Rydz J, Sikorska W, Kyulavska M, Christova D (2014) Polyester-based (bio) degradable polymers as environmentally friendly materials for sustainable development. Int J Mol Sci 16:564-596

9. Väisänen T, Haapala A, Lappalainen R, Tomppo L (2016) Utilization of agricultural and forest industry waste and residues in natural fiber-polymer composites: a review. Waste Manag 54:62-73

10. Atoyebi OD, Awolusi TF, Davies IEE (2018) Artificial neural network evaluation of cement-bonded particle board produced from red iron wood (Lophira alata) sawdust and palm kernel shell residues. Case Stud Constr Mater 9:e00185. https://doi.org/10.1016/j.cscm.2018.e00185

11. Cabral MR, Nakanishi EY, Mármol G, Palacios J, Godbout S, Lagacé R, Junior HS, Fiorelli J (2018) Potential of Jerusalem Artichoke (Helianthus tuberosus L.) stalks to produce cement-bonded particleboards. Ind Crops Prod 122:214-222

12. Ezerskiy V, Kuznetsova NV, Seleznev AD (2018) Evaluation of the use of the CBPB production waste products for cement composites. Constr Build Mater 190:1117-1123

13. He Z, Jia $Y$, Wang $S$, Mahoutian $M$, Shao $Y$ (2019) Maximizing $\mathrm{CO}_{2}$ sequestration in cement-bonded fiberboards through carbonation curing. Constr Build Mater 213:51-60

14. Li M, Khelifa M, Khennane A, El Ganaoui M (2019) Structural response of cement-bonded wood composite panels as permanent formwork. Compos Struct 209:13-22

15. Fan M, Kor M, Zhou X, Noah J (2012) Cement-bonded composites made from tropical woods : compatibility of wood and cement. Constr Build Mater 36:135-140. https://doi.org/10.1016/j.conbuildmat.2012.04.089

16. Hossain MU, Wang L, Iris KM, Tsang DCW, Poon CS (2018) Environmenta and technical feasibility study of upcycling wood waste into cementbonded particleboard. Constr Build Mater 173:474-480

17. Fischer VF, Wienhaus O, Ryssel M, Oldbrecht J (1974) The water-soluble carbohydrates of wood and their influence on the production of lightweight wood-wools boards. Holztechnologie 15:12-19

18. Lee AWC, Hong Z, Phillips DR, Hse CY (1987) Effect of cement/wood ratios and wood storage conditions on hydration temperature, hydration time, and compressive strength of wood-cement mixtures. Wood Fiber Sci 19:262-268

19. Lee AWC, Short PH (1989) Pretreating hardwood for cement-bonded excelsior board. For Prod J 39:68-70

20. Plekhanova TA, Keriene J, Gailius A, Yakovlev Gl (2007) Structural, physical and mechanical properties of modified wood-magnesia composite. Constr Build Mater 21:1833-1838

21. Mors R, Jonkers H (2017) Effect on concrete surface water absorption upon addition of lactate derived agent. Coatings 7:51

22. Zhan BJ, Xuan DX, Poon CS, Shi CJ (2016) Effect of curing parameters on $\mathrm{CO}_{2}$ curing of concrete blocks containing recycled aggregates. Cem Concr Compos 71:122-130

23. Ghosh RK, Rahman MM, Das AK, Rana R, Shams MI (2015) Introducing Areca catechu as a raw material of cement-bonded board through determining the properties of Areca catechu cement-bonded board. J Indian Acad Wood Sci 12:99-103

24. Ciannamea EM, Stefani PM, Ruseckaite RA (2010) Medium-density particleboards from modified rice husks and soybean protein concentratebased adhesives. Bioresour Technol 101:818-825

25. Brasileiro GAM, Vieira JAR, Barreto LS (2013) Use of coir pith particles in composites with Portland cement. J Environ Manag 131:228-238

26. Shalbafan A, Luedtke J, Welling J, Thoemen $H$ (2012) Comparison of foam core materials in innovative lightweight wood-based panels. Eur J Wood Wood Prod 70:287-292

27. Shalbafan A, Luedtke J, Welling J, Fruehwald A (2013) Physiomechanical properties of ultra-lightweight foam core particleboard: different core densities. Holzforschung 67:169-175

28. Indian Jute Industries'Research Association (2010) Development of jutebamboo composites for application in rural areas

29. Scandinavian Pulp Paper and Board Testing Committee (SCAN) (1992) Wood chips for pulp production-bulk density (SCAN-CM 46:92)

30. Eusebio DA (2003) Cement bonded board: today's alternative. In: Technical forum in celebration of the PCIERD 21 st anniversary. Pasig City, Philippine, pp 23-45

31. Nagadomi W, Kuroki Y, Eusebio DA, Ma L, Kawai S, Sasaki H (1996) Rapid curing of cement-bonded particleboard. 3. Effect of sodium hydrogen carbonate and some cement hardening accelerators. Mokuzai Gakkaishi 42:762-768

32. Malaysia Standard Institute-MS 934 (1986) Malaysian standard specification for wood-cement board. SIRIM, Shah Alam

33. RStudio Team (2008) RStudio: Integrated Development for R

34. Revelle W (2017) psych: procedures for psychological, psychometric, and personality research

35. Fox J, Weisberg S (2011) An R companion to applied regression, 2nd edn. Sage Publications, Thousand Oaks

36. Wickham H (2009) ggplot2: elegant graphics for data analysis. Springer, New York

37. Nazerian M, Ghalehno MD, Gozali E (2011) Effects of wood species, particle sizes and dimensions of residue obtained from trimming of wood-cement composites on physical and mechanical properties of cement-bonded particleboard. Wood Mater Sci Eng 6:196-206

38. Ström G, Carlsson G (1992) Wettability of kraft pulps-effect of surface composition and oxygen plasma treatment. J Adhes Sci Technol 6:745-761

39. Börås L, Gatenholm P (1999) Surface composition and morphology of CTMP fibers. Holzforschung 53:188-194

40. ISO 8335 (1987) Cement-bonded particleboards - boards of Portland or equivalent cement reinforced with fibrous wood particles

41. Bureau of Indian Standards (BIS) (1995) Cement bonded particle boards specification (IS 14276)

42. Akaranta $\mathrm{O}$ (2000) Production of particle boards from bioresources. Bioresour Technol 75:87-89

43. Tabarsa T, Ashori A (2011) Dimensional stability and water uptake properties of cement-bonded wood composites. J Polym Environ 19:518-521

44. Ashori A, Tabarsa T, Sepahvand S (2012) Cement-bonded composite boards made from poplar strands. Constr Build Mater 26:131-134

45. Malonney T (1977) Modern particleboard and dry-process fiberboard manufacturing. Miller Freeman Publications, San Francisco

46. Savastano H Jr, Warden PG, Coutts RSP (2003) Mechanically pulped sisal as reinforcement in cementitious matrices. Cem Concr Compos $25 \cdot 311-319$ 
47. Barnes D (2001) A model of the effect of strand length and strand thickness on the strength properties of oriented wood composites. For Prod J 51:36-46

48. Dinwoodie JM, Paxton BH (1989) A technical assessment cement bonded wood particleboard. Constr Build Mater 3:14-21

49. Rachtanapun P, SattayarakT, Ketsamak N (2012) Correlation of density and properties of particleboard from coffee waste with urea-formaldehyde and polymeric methylene diphenyl diisocyanates. J Compos Mater 46:1839-1850
50. Widyorini R, Xu J, Umemura K, Kawai S (2005) Manufacture and properties of binderless particleboard from bagasse l: effects of raw material type, storage methods, and manufacturing process. J Wood Sci 51:648-654

\section{Publisher's Note}

Springer Nature remains neutral with regard to jurisdictional claims in published maps and institutional affiliations.

\section{Submit your manuscript to a SpringerOpen ${ }^{\circ}$ journal and benefit from:}

- Convenient online submission

- Rigorous peer review

- Open access: articles freely available online

- High visibility within the field

- Retaining the copyright to your article

Submit your next manuscript at $\boldsymbol{\nabla}$ springeropen.com 